\title{
Governança Participativa em Moçambique: Dinâmicas do Envolvimento dos Cidadãos na Gestão Municipal em Xai-Xai
}

\section{Participatory Governance in Mozambique: Dynamics of Citizens' Involvement in Municipal Management in Xai-Xai}

Albino Alves Simione

Doutorando em Administração pela Universidade Federal de Minas Gerais. Professor na Universidade São Tomás de Moçambique, Moçambique. simialves@gmail.com

http://lattes.cnpq.br/3973302468007569

Ivan Beck Ckagnazaroff

Doutorado em Doctoral Programme Aston Business School - Aston University. Professor associado do Departamento de Ciências Administrativas e do Cepead da Universidade Federal de Minas Gerais, Brasil.

ivanbeck00@gmail.com

http://lattes.cnpq.br/6536172803067886

Resumo: Neste trabalho, refletimos sobre a institucionalização das instâncias de participação social e envolvimento dos cidadãos na esfera municipal em Moçambique. O objetivo foi analisar os mecanismos de governança participativa concebidos na gestão municipal e suas implicações no processo de tomada de decisão das políticas públicas locais. O estudo é relevante, pois permeia questões fundamentais referentes à democratização da administração pública e à valorização da sociedade civil como um ator político relevante. Realizamos um estudo de caso sobre as experiências adotadas no município de Xai-Xai. A pesquisa se caracteriza como qualitativa, descritiva e interpretativa, desenvolvida por meio de documentos e entrevistas submetidos à análise de seu conteúdo. Os resultados apontam a implementação dos conselhos locais como a forma principal de participação cidadã estabelecida, contudo, os diferentes dispositivos adotados apresentam falhas na estrutura de representação e no funcionamento, que podem comprometer as virtualidades da interação social e 0 processo de gestão democrática.

Palavras-Chave: Participação, Gestão Democrática, Conselhos Locais, Políticas Públicas.

Abstract: In this paper we discuss about the institutionalization of social participation scopes and the citizens' involvement with the municipalities in Mozambique. The aim of this work is to analyze the participatory governance mechanisms designed for the municipal management and their implications in the decision-making process of local public policies. This study is important because it delves into the fundamental issues of democratizing the public administration and examines the civil society as a relevant political actor. We conducted a case study regarding the experiences that were embraced in the city of Xai-Xai. The research is characterized as qualitative, descriptive and interpretative. It was developed through interviews and documents that were submitted to content analysis. The results show the establishment of local councils as the main form of implemented citizen participation. However, the set of distinctive practices that was adopted in Xai-Xai has flaws in its structure of representation and in its functioning, which can compromise the social interaction and democratic management process.

Keywords: Participation, Democratic Management, Local Councils, Public Policies.

Texto completo em português: http://www.apgs.ufv.br Full text in Portuguese: http://www.apgs.ufv.br

\section{INTRODUÇÃO}

Os discursos acerca da Governança Participativa (GP) surgiram em Moçambique nos finais da década de 1990 e tornaram-se a marca principal da política e da administração pública no início dos anos de 2000, período em que as principais experiências de participação pública foram implementadas. Eles emergiram sucedendo basicamente três cenários que decorreram de forma interligada e que marcaram o contexto político e econômico nacional nos anos antecedentes.

Primeiro, surgiram como complemento das transformações políticas e econômicas intensas que foram introduzidas pela Constituição da República de Moçambique (CRM) de 1990. A constituição produziu uma reforma do Estado que modificou o sistema político de poder popular socialista e o regime de governo de partido único dirigido pela Frente de Libertação de Moçambique (FRELIMO), que haviam sido instaurados em 1975 quando do alcance da independência nacional do regime colonial português.

A CRM de 1990 introduziu um novo sistema político, fundamentado nos princípios da democracia pluripartidária, e alterou o modelo de planejamento centralizado da economia, estabelecendo um sistema de livre concorrência. Além disso, a constituição introduziu várias reformas no caráter centralizador da administração pública de então, com a descentralização para os governos provinciais e distritais de maiores poderes decisórios e competências próprias para a implementação das políticas públicas.

Segundo, emergiram com a estabilização política e social promovida pela assinatura do Acordo Geral de Paz (AGP) de 1992, que pôs fim ao conflito armado iniciado em 1976, opondo o Governo de Moçambique (dirigido pela FRELIMO) ao Movimento de Resistência Nacional (RENAMO), uma força de oposição ao regime instituído na época e reivindicava a partilha do poder político. O ambiente de paz vivenciado no país decorrente do fim do conflito consequentemente permitiu a reorganização das estruturas do aparelho estatal e da sua administração, possibilitando ampliar a presença da representação do Estado e de suas instituições no território nacional.

A partir da segunda metade da década de noventa, influenciadas pelo processo de reorganização administrativa que decorria, foram introduzidas no setor público moçambicano novas

Correspondência/Correspondence: Albino Alves Simione. Secretaria Provincial de Gaza, Departamento de Administração Territorial e Autárquica. Av. Samora Machel, Recinto do Governo Provincial Cidade Baixa. Xai-Xai, - Moçambique. simialves@gmail.com 
formas de governança. O foco principal foi a introdução de modelos e mecanismos de gestão fundamentados na gestão por resultados, no conceito de accountability e em arranjos de participação da sociedade, visando à melhoria do desempenho dos serviços públicos e à inclusão de cidadãos comuns e grupos de interesses como atores políticos importantes nas decisões administrativas.

Terceiro, surgiram como resultado da emenda constitucional de 1996 e implementação da descentralização do tipo municipalização. A emenda constitucional criou o Poder Local e institucionalizou a descentralização na escala local municipal, possibilitando o exercício e partilha do poder político. Ela alterou a estrutura político-administrativa do Estado, que passou a ser constituída por três níveis de governo: os Órgãos Centrais (OC), representados pelos ministérios e agências nacionais, os Órgãos Locais do Estado (OLE), representados pelos governos provinciais e governos distritais, e os Órgãos do Poder Local (OPL), representados pelos municípios.

Vale destacar que, no âmbito das transformações políticas e institucionais verificadas nesse período, foi aprovada a Lei $n^{\circ}$ 2/1997, de 18 de fevereiro, por meio da qual foram criados no país os primeiros 33 municípios, e desde 1998 são eleitos periodicamente os respectivos governos municipais. Atualmente existem em Moçambique 53 municípios. Na organização administrativa do país, os municípios correspondem às circunscrições dos territórios das cidades e vilas.

Podemos afirmar em termos gerais que as ideias sobre a GP se tornaram predominantes no contexto dos esforços de construção do Estado democrático, do fortalecimento da cidadania ativa e da criação de mecanismos para a gestão democrática na escala local. Elas surgiram no quadro do estabelecimento de um sistema democrático participativo orientado pelo ideal político que se fundamenta na interação entre o poder público e a sociedade. Após a implementação da Estratégia Global de Reforma do Sector Público (2001-2011), as propostas da GP se tornaram num dos pressupostos básicos da promoção de práticas de inclusão democrática no país.

A GP é definida segundo Speer (2012, p. 2379) como um conjunto de arranjos institucionais que têm por objetivo facilitar a participação de cidadãos comuns no processo das políticas públicas. Eles envolvem os cidadãos, por exemplo, na tomada de decisões sobre a distribuição dos fundos públicos entre as comunidades e o desenho de políticas públicas, bem como a avaliação e monitoramento dos gastos do governo.

As práticas de GP em Moçambique têm sido apresentadas com o objetivo de aperfeiçoar e consolidar a democracia (Canhanga, 2009; Nguenha, 2009) e como um conjunto de princípios e instrumentos de gestão (Forquilha \& Orre, 2012; Nylen, 2014) cuja finalidade é fomentar, de modo abrangente, a participação dos diferentes atores políticos e sociais na administração pública. A ideia central é o estabelecimento, nos OPL (municípios) e OLE (distritos), de mecanismos participativos embasados em novas estruturas de interação e relacionamento entre o governo e a sociedade que possibilitem a melhoria da atuação da administração pública e da prestação de serviços públicos.

Especificamente os OPL têm como objetivos organizar a participação dos cidadãos na solução dos problemas próprios da sua comunidade e promover o desenvolvimento local. Eles buscam ampliar a cidadania e conscientizar a sociedade para tomar parte nos assuntos políticos que se sucedem nesse nível. Portanto, o processo de participação pública visa colocar o cidadão como um ator indispensável na tomada de decisões acerca dos assuntos que são considerados serem de seu interesse e permitir uma maior interdependência e articulação entre os diferentes atores sociais, de tal modo que seja garantida uma maior democratização da administração pública.

Sob essa nova conjuntura de gestão pública, espera-se que práticas como o dirigismo, o centralismo decisório e o planejamento tecnocrático, que ignoram a aspiração dos indivíduos pela participação, transformem-se e que os novos padrões de articulação social promovidos pela GP sejam introduzidos como uma alternativa para aprimorar a gestão pública. No entanto, em paralelo a esses mecanismos participativos, emergem alguns questionamentos sob pelo menos duas perspectivas indispensáveis: quais as proposições teóricas que embasam a GP? Como ocorre a implementação da GP em Moçambique? Qual a dinâmica sociopolítica e administrativa que caracteriza a participação cidadã no contexto municipal?

Este trabalho visa contribuir para a literatura sobre a GP com uma reflexão sobre como tem decorrido a implementação de seus princípios, mecanismos e instrumentos, apresentando a sua contribuição na promoção do envolvimento da sociedade no governo em um país com baixos índices de desenvolvimento. $O$ problema de pesquisa tratado é: em que extensão as iniciativas de GP adotadas em Moçambique incluem os atores da sociedade nos processos decisórios das políticas públicas na escala municipal? O objetivo é analisar os mecanismos de GP concebidos na gestão municipal e suas implicações no processo de tomada de decisão das políticas públicas locais.

$\mathrm{O}$ artigo é constituído por cinco partes. Na próxima, apresentamos uma discussão acerca da GP e os seus desenvolvimentos teóricos recentes na literatura internacional. $\mathrm{Na}$ terceira, apresentamos os procedimentos metodológicos utilizados para a construção deste artigo e realizamos uma breve descrição da situação socioeconômica da unidade pesquisa, que é o município de Xai-Xai. Em seguida, na quarta, apresentamos os resultados e a discussão da análise efetuada. Finalmente, na última parte, tecemos algumas considerações e avançamos possíveis desdobramentos para pesquisas futuras.

\section{FUNDAMENTAÇÃO TEÓRICA}

Nesta seção realizamos uma revisão da literatura sobre a GP. Inicialmente efetuamos o enquadramento geral dos estudos sobre a temática destacando quatro perspectivas teóricas que se ocupam da análise dos processos participativos. Em seguida, apresentamos as concepções e os princípios que embasam a ideia de GP como mecanismo de envolvimento da sociedade no 
processo decisório das políticas públicas. Expomos mais adiante algumas críticas que são feitas a essa abordagem, ressaltando as limitações que são apontadas à sua aplicabilidade no processo de gestão pública.

\subsection{A Governança Participativa}

As discussões sobre as questões da GP tiveram sua origem a partir da segunda metade do século XX e destacam-se na literatura internacional no âmbito do que se tem designado de New Governace Paradigm (OSBORNE, 2006). Atualmente, a GP possui um enorme conjunto de abordagens teóricas, sendo referenciada sobretudo nas análises que exploram as virtudes positivas, inovações e limitações da introdução do modelo de participação social no processo de gestão pública (Chhotray \& Stoker 2009; Gaventa \& Barrett, 2012; Farazmand, 2012). No contexto nacional de Moçambique, existem trabalhos importantes que abordam o tema da participação no nível distrital (Forquilha \& Orre, 2012) e no âmbito das experiências da gestão municipal (Nguenha, 2009; Canhanga, 2009).

Essencialmente, os trabalhos existentes, tanto os nacionais quanto os internacionais, abordam a GP como um conjunto de princípios e instrumentos políticos e administrativos que compreendemos estar enquadrados principalmente em quatro perspectivas de análise importantes. A perspectiva da democrática participativa, como assinalam Brardhan (2002) e Crook (2003), vê a GP como um mecanismo voltado para o reforço da democracia local por meio do envolvimento da população na tomada de decisões sobre as políticas públicas e ampliação da responsabilização política e administrativa dos governos locais. A perspectiva da democracia deliberativa inspirada nas proposições de Habermas (1995) é pautada no diálogo entre os atores estatais e a sociedade civil, por meio de espaços deliberativos. A GP é entendida aqui, segundo Speer (2012), como formas deliberativas de tomada de decisão que privilegiam cooperação, debate público e coletivo para a promoção do bem comum.

A perspectiva do empoderamento da sociedade, de acordo com Roberts (2004), trata a GP como conjunto de princípios voltados à promoção e aplicação de estratégias para a emancipação social, ampliação dos direitos de cidadania e o acesso individual e coletivo aos espaços públicos. Ainda, a perspectiva da auto governança, segundo Osborne (2006), encara a GP como um modelo de provisão de serviços públicos a partir do intercâmbio e envolvimento do governo com vários atores dos setores privado lucrativo e voluntário e a criação de redes e vínculos interorganizacionais. Limitaremos nossa reflexão neste trabalho às duas primeiras perspectivas citadas acima.

A despeito dessas abordagens, cabe destacar que a GP é, conforme Pateman (2012), uma corrente em favor da democracia deliberativa, incorporando dela tópicos considerados emergentes, tais como grupos de interesses e redes de políticas que vem alterar de forma significativa a concepção e a natureza da administração pública e da gestão das políticas públicas. Ela seria uma forma de restabelecimento da legitimidade do sistema político pela criação de novos canais de participação e interação inspirados nas teorias que apelam para o conceito da good governance, que enfatiza o estabelecimento de condições de governabilidade e a gestão compartilhada e interinstitucional envolvendo os setores público, produtivo e voluntário.

A GP é definida segundo Smith (2009) como um arranjo institucional que tem como finalidade possibilitar a integração do público nos processos decisórios sobre as políticas públicas permitindo, desta feita, a democratização do sistema político, o qual é conduzido dentro de um espírito de deliberação e contestação de ideias que favorecem os resultados e a qualidade das políticas públicas. De acordo com Speer (2012), ela se refere a um conjunto de arranjos institucionais que têm por objetivo facilitar a participação de cidadãos comuns no processo de desenho de políticas públicas, bem como a avaliação e o monitoramento dos gastos do governo.

No entender de Gaventa (2012), a GP é um mecanismo de inclusão da população nas estruturas de tomada de decisão sobre as políticas públicas que permite incrementar e fortalecer as capacidades de intervenção das camadas sociais mais desfavorecidas e superar as estruturas políticas e de poder tradicionais. O que essas definições asseveram, como explica Grindle (2007), é que na abordagem da GP os cidadãos eleitores ganham um novo tratamento baseado no seu maior envolvimento nos espaços públicos e ambientes institucionais, resultando, assim, numa expansão dos interesses coletivos e num maior exercício da cidadania.

Portanto, ela estabelece instâncias de intervenção que vinculam a ação governamental com os cidadãos por meio de relacionamentos nos espaços deliberativos que servem para envolver os cidadãos, movimentos sociais e outros grupos de interesse no setor público, o que pode garantir maior legitimidade às iniciativas governamentais. Nesse ponto de vista, a GP englobaria tanto as visões que embasam a democracia participativa quanto as que defendem a democracia deliberativa nos espaços públicos (fóruns locais, conselhos, consulta comunitária, audiência pública, associações públicas, ente outros). Já a noção de democracia deliberativa considera a inter-relação entre diferentes atores políticos e sociais, que, a partir de seus valores e capacidades comunicativas, enfrentam o desafio do diálogo público com vistas à construção de políticas públicas de um modo colaborativo.

A democracia participativa e a deliberativa possuem uma relação de articulação como modelos de participação e representação. De acordo com Smith (2009), a primeira tem o seu enfoque no alargamento da participação cidadã na gestão pública e processos de planejamento associados às ações de formulação e fiscalização das políticas públicas por meio de vários atores individuais ou coletivos em torno de interesses comuns. Ela implica também a ideia de institucionalização de estruturas de representação pautadas em representantes escolhidos ou eleitos pela própria sociedade civil e pelo governo.

A segunda implica, conforme Lüchmann (2006), que a deliberação incorpora a ideia de que as escolhas políticas são legitimadas dentro de uma interação entre os agentes que 
possuem direitos e liberdades iguais no exercício da cidadania, especialmente para influenciar as ações governamentais. Portanto, a ação deliberativa considera a inclusão dos diferentes atores sociais, a abertura do debate e a cooperação e o diálogo centrados na ampliação dos espaços públicos e mecanismos de discussão coletiva passíveis de justificar e legitimar as decisões tomadas.

Isso quer dizer que a criação de arranjos de GP configura uma forma de exercício coletivo do poder político, que se realiza de acordo com Nabatchi e Amsler (2014) por meio do engajamento direto no nível local de governo. Visto que a participação tende a ampliar a presença de atores sociais de diversos tipos no âmbito da tomada de decisão das políticas públicas, ela possibilitaria o aumento da cidadania por meio da inclusão de movimentos sociais e atores socialmente excluídos, reduzindo dessa forma a tensão gerada pelo problema da representação e da legitimidade políticas.

É dentro dessas concepções que Cornwall e Coelho (2007) explicam que em contextos participativos a ação coletiva tende a ser possibilitada pelo interesse de abertura da administração pública para a interação com novos atores da sociedade, mas também pela capacidade de ação dos representantes da sociedade civil e pelo acesso à informação por parte da população. Da mesma forma, em contextos deliberativos, a ação coletiva estaria baseada na criação de estruturas de interação política em que os atores da sociedade são percebidos pelo governo como importantes na discussão das políticas públicas, contribuindo para fortalecer o interesse da coletividade e a legitimidade das iniciativas governamentais e seus resultados.

Trata-se de uma desmonopolização dos processos decisórios pela realização de mudanças nas formas tradicionais de administração, com a realização de transformações administrativas que visam reduzir a intervenção técnica exclusiva da administração e o monopólio do poder decisório dos burocratas e políticos para favorecer a intervenção coletiva e formação de redes que ampliam o diálogo e a intervenção junto ao Estado. $O$ fundamento central desses argumentos, como destaca Gonzáles (2015), é que na abordagem participativa a interação entre os cidadãos e o governo gera envolvimento efetivo nas etapas cruciais de tomada de decisão das políticas públicas, elevando a confiança e a legitimidade.

$\mathrm{Na}$ mesma linha, Koch (2013) pontua que os arranjos institucionais engendrados pela GP podem melhorar o papel político da sociedade civil e promovem a inclusão política, favorecendo a formação de identidades coletivas que possibilitam uma efetiva partilha de poder e de recursos que estão disponíveis. Esses espaços de participação têm um grande potencial para gerar resultados positivos nas ações implementadas pela máquina pública, por exemplo, consensos sobre os conteúdos da política pública local, orçamentos participativos, prioridades de intervenção a considerar, entre outros aspectos.

No entanto apesar de a GP ser apresentada em certa literatura de uma forma positiva, existem, contudo, limitações e dilemas das práticas decorrentes da complexidade da participação cidadã (Roberts, 2004, p. 326). Tais complexidades referem-se à qualidade das redes de atores que são formadas; aos interesses que envolvem os diferentes grupos que participam dos processos de gestão; ao conflito nos processos decisórios e das escolhas de prioridades; às condições estruturais e políticas da organização dos grupos; e à legitimidade dos interesses políticos da sociedade civil que produzem um impacto nos resultados da democracia.

Em determinadas realidades, ela pode não significar efetivamente a constituição de espaços de deliberação que promovem a equidade, a formação de vínculos sociais inclusivos que contribuem na prática para o desenvolvimento das políticas públicas. Baseados numa perspectiva crítica dos resultados da GP em vários países, Gaventa e Barrett (2012) e Koch (2013) afirmam que a participação produz resultados positivos, que são muitas vezes também acompanhados de efeitos negativos.

A crítica central expressa que a capacidade da GP de engajar os cidadãos depende do acesso às informações necessárias para participarem na vida democrática e assim ampliar o exercício dos seus direitos. Por exemplo, a participação na gestão depende da capacidade de exigir a prestação de contas e a responsabilidade efetiva dos governos locais, bem como do grau de envolvimento dos indivíduos nos esquemas ou arranjos de GP (seja nas redes, conselhos ou comités), ao mesmo tempo que implica o conhecimento de regras e a mobilização da sociedade para a defesa dos seus interesses.

A GP precisa, assim como defendem Bryson, Quick, Slotterback e Crosby (2012), ser vista sob a ótica da realidade institucional em que ela é aplicada e considerar dimensões que têm sido pouco exploradas por diversos estudos, como a história dos lugares e o ambiente sócio-espacial. É necessário dar atenção aos contextos em que os desenhos institucionais de GP são aplicados e reconhecer a existência de singularidades dos "lugares", portanto, que existem dimensões políticas/práticas, políticas/valores e geográficas que podem operar como barreiras ou oportunidades para o estabelecimento das instâncias democráticas de participação na esfera pública.

Nessa ótica, em contextos específicos de países em desenvolvimento como Moçambique, interessa analisar o contexto e a dinâmica que envolve os processos participativos. O estudo desses aspectos possibilita ampliar a compreensão sobre os resultados produzidos pelos arranjos de GP, mas permite compreender, também, como é encarada a ideia de envolvimento dos cidadãos na gestão pública e a forma como acontece a interação social.

\section{PROCEDIMENTOS METODOLÓGICOS}

Neste trabalho, empreendemos uma análise caracterizada como qualitativa, dado que o problema de pesquisa demandou uma investigação de cunho descritivo e interpretativo (Godoy, 2010). É um estudo de caso (Yin, 2005) selecionado pela sua pertinência teórica em relação ao objetivo da pesquisa, e pela sua pertinência prática dado a possibilidade de se aprender com as experiências referentes a GP nele evidenciadas. 
A construção do estudo compreendeu duas etapas, nas quais utilizamos o método de Análise de Conteúdo ( $A C)$ para os dados coletados. Segundo esclarece Bardin (2004), a AC permite abranger as comunicações tanto verbais ou não-verbais quanto linguísticas, mas também documentos, mediante procedimentos sistemáticos e objetivos de descrição do conteúdo das informações obtidas, possibilitando a inferência de conhecimentos relativos às condições e sentido das mensagens.

$\mathrm{Na}$ primeira etapa da pesquisa, realizamos inicialmente um levantamento de documentos (legislação referente à gestão democrática no contexto moçambicano), relatórios (do executivo do município de Xai-Xai) e atas (dos conselhos locais). A finalidade desse procedimento foi, por um lado, identificar as diretrizes da GP que expressam a forma como a participação da sociedade na gestão é concebida ou encarada pelo poder público em Moçambique e, por outro, recolher relatos sobre o funcionamento dos espaços constituídos.

$\mathrm{Na}$ AC efetuada, seguimos a constituição do corpus da análise, que se baseou nas concepções e padrões da proposta de GP no país. Para o efeito, utilizamos como critério de análise as diretrizes que fundamentam a adoção dos arranjos de GP. Por meio desse procedimento analítico essencialmente, identificamos os princípios que foram propostos para a criação de instâncias de participação pública; os seus pressupostos; as bases teóricas sobre as quais foram estabelecidos; o quadro institucional; e as condições administrativas que permeiam 0 processo de estabelecimento das práticas de GP na esfera municipal. A análise contemplou além disso a verificação do alinhamento dessas concepções em relação às proposições teóricas apresentadas na literatura.

A segunda etapa consistiu na utilização da técnica de entrevistas para treze entrevistados escolhidos intencionalmente e se baseou em um roteiro não estruturado. Os critérios utilizados nessa escolha foram as posições que eles possuem e o papel que desempenham no processo de promoção da participação pública no caso pesquisado. Os agentes públicos (o autarca - o mesmo que prefeito, vereadores e técnicos dos diferentes setores do município pesquisado) e representantes da sociedade civil (presidente e gestor de programas do fórum das ONGs de Gaza) foram os atores entrevistados na pesquisa. Esses dois grupos de respondentes foram selecionados porque se constituíram como os atores relevantes que interagem no âmbito das arenas de participação pública no município de Xai-Xai e que poderiam fornecer as informações necessárias para o alcance dos objetivos definidos para a pesquisa.

Conforme destaca Mattos (2006), essa técnica possibilita a obtenção de informações relevantes e significativas que permitem o esclarecimento de situações, atitudes e comportamentos em uma determinada complexidade social. As situações referentes a este estudo foram consideradas a partir da ótica dos entrevistados relativamente às questões sobre: quem participa nos arranjos estabelecidos; como é feita a seleção de membros que integram tais instâncias; qual é a representação dentro desses arranjos; e qual o seu contributo para as políticas públicas municipais.
A análise do caso pesquisado se restringiu especialmente a duas dimensões importantes da GP, que, conforme apontam Salvador e Ramió (2011), podem ser observadas no processo de constituição de mecanismos de participação social. A primeira dimensão refere-se à institucionalização das instâncias de participação pública e está relacionada às formas pelas quais é processada a inclusão dos cidadãos e grupos de interesse e à representatividade dentro dessas instâncias. A segunda dimensão tem a ver com a dinâmica que caracteriza o envolvimento dos cidadãos e se preocupa com os aspetos alusivos à ação, às assimetrias e às posições ocupadas pelos atores dentro das instâncias de participação que são estabelecidas.

Através da $\mathrm{AC}$, procedemos ao exame individual dos textos resultantes da transcrição das entrevistas e buscamos descobrir neles conjuntos de significações com base em recortes e agregação de frases e extratos das falas (consideradas pertinentes-significativas) dos respondentes, em que são ressaltados ou descritos aspectos, elementos ou características que traduzam o processo de participação pública implementado no município de Xai-Xai. Esses conjuntos de significações se constituíram como os elementos do corpus da análise sobre o qual classificamos as práticas de envolvimento dos cidadãos que foram adotadas. A partir dessa classificação, realizamos a interpretação das experiências de participação pública mediante um procedimento inferencial, conforme expressavam as formas pelas quais se dá GP na realidade pesquisada.

\subsection{Breve Caracterização Socioeconômica do Município de Xai-Xai}

O Município de Xai-Xai é a capital e a cidade mais importante da Província de Gaza. Situa-se na região sul e foi estabelecido em 1998 quando das primeiras eleições municipais em Moçambique. Possui grande diversidade cultural e linguística, destacando-se, para além do português (língua oficial), o Changana, que predomina como língua nacional mais utilizada.

A cidade é dividida em quatro unidades administrativas denominadas postos administrativos, sendo elas o Posto Administrativo Sede, o Posto Administrativo da Praia de Xai-Xai, o Posto Administrativo de Inhamissa e finalmente 0 Posto Administrativo de Patrice Lumumba. Os postos administrativos estão subdivididos em doze bairros, sendo que $20 \%$ da população vive nos bairros da zona central, e os restantes $80 \%$, nas periferias.

De acordo com os dados do censo de 2007 (INE), a cidade possui 124.216 habitantes, que representam uma distribuição irregular, constituída por uma pirâmide etária de base muito larga, característica de uma sociedade onde predominam crianças e jovens (39\% com menos de 15 anos) e uma esperança de vida de 50 anos. A taxa anual de crescimento da população é de $4 \%$, e a mortalidade infantil é de 200/1000.

A agricultura é praticada na zona Peri Urbana por $70 \%$ da população como a atividade econômica mais importante. Os restantes $30 \%$ da população estão envolvidos majoritariamente no setor de serviços, distribuindo-se pelas atividades de comércio 
informal, pequeno varejo, alojamento e restauração, mecânicaauto, prestação de serviços a empresas, gráfica e artesanato (INE, 2007).

As grandes indústrias transformadoras da cidade (as fábricas de descasque e processamento da castanha de caju, de descasque de arroz e de refrigerantes) encontram-se todas encerradas existindo, contudo, uma considerável atividade na área de construção civil. A administração pública emprega 4421 servidores públicos (DFP, 2015), apresentando-se como um dos principais empregadores formais na cidade.

No que diz respeito à educação, $48 \%$ da população é alfabetizada e $71 \%$ frequentam ou já frequentaram a escola, ainda que majoritariamente somente até aos níveis primário e fundamental (Perfis Municipais, 2013). Relativamente às infraestruturas sociais, existe na cidade uma rede de escolas, sendo 59 do nível primário, 11 do nível fundamental, 7 escolas do nível médio, entre públicas e privadas. Destacam-se igualmente na área de educação técnico-profissional 4 escolas, sendo 2 de nível médio, 1 de nível fundamental e 1 instituto de magistério, respectivamente. A cidade conta com 2 universidades privadas.

Existem na cidade 5 unidades de saúde básicas e 1 hospital de nível provincial (o maior e de referência para toda a província), bem como 3 postos de saúde privados. A cidade conta ainda com uma rede de diversos centros comerciais, mercados e agências bancárias que respondem às necessidades socioeconômicas da população. Dentre as vias de acesso na cidade, $90 \%$ são constituídas majoritariamente por estradas de terra. Do total, $56 \%$ da população têm acesso a água tratada e $46,2 \%$, a energia elétrica. A percentagem de casas com saneamento é de $57,5 \%$ (INE, 2007).

\section{APRESENTAÇÃO E DISCUSSÃO DOS RESULTADOS}

Nesta seção, apresentamos os resultados da pesquisa a partir de duas linhas principais: na primeira, expomos a institucionalização das instâncias de participação social, em que destacamos as diretrizes sobre o quadro institucional legal, suas concepções e pressupostos, bem como as formas de constituição de tais instâncias participativas. Na segunda, apresentamos as experiências de participação implementadas no município de XaiXai, que envolvem o estabelecimento dos conselhos locais (CLs), da governação aberta e da articulação entre gestores municipais e comunidade. Adiante fazemos uma discussão sobre esses diferentes aspectos.

\subsection{A Institucionalização da Governança Participativa em Moçambique}

Observamos que, no contexto moçambicano, a GP foi estabelecida pelo governo por diretrizes que preveem a articulação entre o Estado e as entidades da sociedade civil, por meio da criação e implementação de mecanismos de consulta e participação popular que estão voltados a influenciar na elaboração da agenda e ações dos diferentes entes governamentais (municipais e distritais). O Quadro 1 apresenta de forma resumida o enquadramento dado ao processo de construção dessas instâncias de participação no país.

Quadro 1: Fundamentos do processo de participação

\begin{tabular}{|c|c|}
\hline Diretrizes da Gestão Participativa & Descrição \\
\hline $\mathrm{O}$ quadro institucional legal & 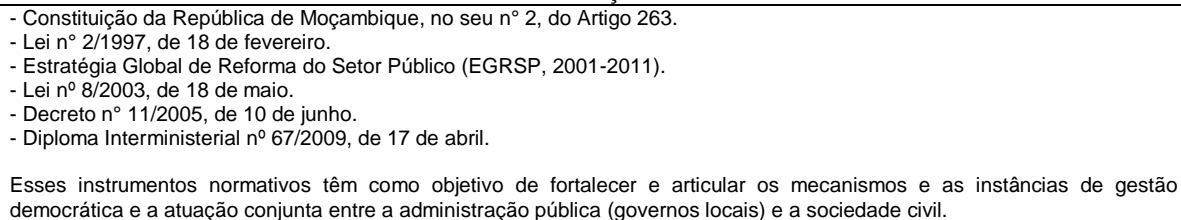 \\
\hline As concepções e pressupostos da GP & $\begin{array}{l}\text { - Participação social como direito do cidadão e expressão de sua autonomia. } \\
\text { - Consolidação da democracia através da participação como método de governo. } \\
\text { - Promoção de mecanismos de mobilização da sociedade civil. } \\
\text { - Participação dos cidadãos em reuniões e discussões sobre assuntos públicos. } \\
\text { - Influência das ações dos governos locais pela apresentação de opinião. } \\
\text { - Equilibrar a relação entre a vontade política dos governantes e o interesse público. } \\
\text { - Participação popular na formulação, na execução, no monitoramento e na } \\
\text { avaliação de programas e políticas públicas. } \\
\text { - Direito à informação, à transparência e ao controle social nas ações públicas. }\end{array}$ \\
\hline A constituição das instâncias de participação & $\begin{array}{l}\text { - Participação da sociedade civil. } \\
\text { - Envolvimento de lideranças comunitárias. } \\
\text { - Vinculação dos membros das arenas às associações ou grupos de interesse. } \\
\text { - Reprentantes do poder público. } \\
\text { - Garantia da diversidade entre os representantes da sociedade civil. } \\
\text { - Critérios para os processos de escolha e indicação dos representantes das } \\
\text { comunidades locais. }\end{array}$ \\
\hline
\end{tabular}

Fonte: Elaboração baseada nos documentos selecionados para o estudo

Em termos gerais, conforme mostra o quadro acima, as diretrizes que fundamentam a proposta de GP buscam institucionalizar mecanismos que asseguram o exercício da cidadania e a construção social. Nesse sentido, elas se baseiam na criação das instâncias de participação que visam permitir a implementação e perpetuação de um modelo de gestão democrática inspirado no estabelecimento de arranjos participativos nos quais é privilegiada a inclusão das pessoas que são implicadas pelos desdobramentos dos processos decisórios sobre as políticas públicas nas esferas municipal e distrital de governo.

\subsubsection{As Instâncias de Participação no Contexto Municipal}

Observamos que a abordagem político-participativa que tem sido implementada no contexto da gestão do município de Xai-Xai configura uma mesclagem de práticas de participação social e a convivência de três formas ou mecanismos de envolvimento da população nos assuntos sobre as políticas públicas municipais, como ilustrado no Quadro 2. 
Quadro 2: Caracterização da participação pública na gestão municipal

\begin{tabular}{|c|c|c|}
\hline \multicolumn{3}{|c|}{ Mecanismos de Envolvimento dos Cidadãos } \\
\hline 1. Conselhos Locais & 2. Governação Aberta & $\begin{array}{l}\text { 3. Articulação Gestores } \\
\text { Municipais e Comunidade }\end{array}$ \\
\hline $\begin{array}{l}\text { Criação de práticas de participação que privilegiam a } \\
\text { organização da população por meio de conselhos } \\
\text { locais (CLs) nos quatro postos administrativos } \\
\text { municipais e um que representa a cidade, que atuam } \\
\text { como mecanismos para influenciar o processo de } \\
\text { tomada de decisão sobre os investimentos públicos e o } \\
\text { financiamento dos projetos de desenvolvimento } \\
\text { municipal. }\end{array}$ & $\begin{array}{l}\text { Estabelecimento de mecanismos de interação social que } \\
\text { envolvem a realização de encontros periódicos } \\
\text { (reuniões populares) de auscultação pública dos } \\
\text { cidadãos munícipes e dirigidas pelo autarca (prefeito) } \\
\text { nos diferentes bairros que compõem os quatro postos } \\
\text { administrativos municipais, e têm como objetivo discutir } \\
\text { os sobre os resultados do exercício da governação } \\
\text { municipal. }\end{array}$ & $\begin{array}{l}\text { Utilização de reuniões públicas como mecanismo voltado } \\
\text { para resolução de problemas nos bairros, identificados } \\
\text { juntamente com a população e os decorrentes da } \\
\text { implementação dos programas e planos de ação do } \\
\text { executivo municipal, representando forma da } \\
\text { acompanhamento das ações governamentais e intervenção } \\
\text { direta dos vereadores e representantes dos vários setores } \\
\text { e departamentos. }\end{array}$ \\
\hline
\end{tabular}

Fonte: Elaboração baseada nas entrevistas do estudo no município de Xai-Xai

A variedade de práticas participativas, conforme ilustrado acima, sugere que o poder público municipal considera que elas podem contribuir para melhorar a sua articulação com a sociedade e se enquadram na perspectiva de que o processo de envolvimento dos cidadãos nas decisões administrativas não pode se restringir apenas a alguns grupos, devendo estar aberto à ampla participação das pessoas nas decisões do governo. Podemos, assim, afirmar que é uma abordagem que considera que participação democrática deve ser ampliada por meio de múltiplas instâncias como forma de assegurar o exercício da cidadania e influência sobre as políticas públicas locais.

\subsection{Discussão: As Diretrizes da Gestão Participativa}

Conforme apresentado no Quadro 1, as concepções sobre a participação em Moçambique foram estabelecidas no $n^{\circ} 2$ do artigo 263 da CRM, que expressa a garantia da participação ativa dos cidadãos nas decisões da administração pública. Essas ideias foram desenvolvidas no artigo 28 da Lei $n^{\circ} 2 / 1997$, de 18 de fevereiro, referente ao modo de integração dos grupos locais na tomada de decisões dos OPL (municípios). Com as devidas ressalvas, entendemos que tais concepções estariam alinhadas às proposições teóricas das abordagens da democracia participativa e da democracia deliberativa, na medida em que incorporam especialmente as ideias que incentivam o envolvimento de diversos atores individuais ou coletivos para influenciar as decisões sobre as políticas públicas governamentais e a deliberação baseada nos espaços públicos por meio dos quais os diferentes atores sociais e políticos interagem, coordenando seus pontos de vista na formação do interesse comum fundamentado na vontade geral e no entendimento mútuo.

No entanto, compreendemos que os ideais dessa nova tendência na gestão pública moçambicana foram aperfeiçoados no âmbito da implementação da Estratégia Global de Reforma do Setor Público (EGRSP) na fase I (2001-2005) e na fase II (20062011) aprovada pelo governo em 2001, que estabelecera a participação social na gestão como um dos pilares do processo governativo e componente fundamental para a melhoria dos processos de tomada de decisão e do desempenho da administração pública (Ciresp, 2001, p. 18).

Nessa perspectiva, as instâncias de participação comunitária, especificamente os CLs, foram então institucionalizados pela Lei № 8/2003, de 18 de maio, que estabelece a organização e funcionamento dos OLE (distritos) e regulamentadas pelo Decreto $n^{\circ} 11 / 2005$, de 10 de junho. Este último estabeleceu a forma de integração das comunidades e dos líderes tradicionais (que são as autoridades comunitárias que exercem um poder baseado nos costumes e práticas políticas tradicionais e legitimado no seio das respectivas comunidades e são formalmente reconhecidas pelo Estado) nos processos de gestão pública.

Importa esclarecer que, inicialmente, essas duas normas instituíram as bases para a criação dos CLs no contexto dos OLE e não dos OPL e definiram que os seus órgãos "asseguram a participação dos cidadãos, das comunidades locais, das associações e de outras formas de organização, que tenham por objeto a defesa dos seus interesses, na formação das decisões que Ihes disserem respeito". Pretendeu-se a formalização das arenas participativas como mecanismo de influência das ações dos governos locais pela apresentação de opinião e formação da vontade geral acerca das políticas públicas. As primeiras experiências de criação de CLs nos OLE surgiram em 2006, e sua missão era basicamente colaborar com a preparação de projetos de desenvolvimento local comunitário.

Com a introdução do Diploma Interministerial nำ67/2009, de 17 de abril, foram delineados formalmente os princípios e critérios para a constituição e estruturação formal dos CLs no âmbito dos OLE. Os conselhos nos OLE possuem competências alargadas para atuarem em desenvolvimento econômico, saúde, educação, agricultura, transportes, e policiamento comunitário e são compostos por 20 membros na Localidade, que é a subunidade administrativa territorial abaixo do Posto Administrativo, 40 membros no Posto Administrativo, que é a unidade administrativa territorial do Município ou do Distrito, e 50 membros no distrito, que é a unidade administrativa territorial da Província.

A despeito desse diploma normativo e de a estrutura de composição dos conselhos neles definidos terem sido originalmente instituídos para a criação dos CLs nos OLE, eles foram também aplicados e adaptados na cidade de Xai-Xai, tendoos como o referencial para a constituição dos seus CLs municipais. Isso se deve à inexistência de instrumentos e diretrizes que regulamentam a criação dos CLs ou de outras instâncias participativas que sejam específicos à realidade municipal.

De forma geral, podemos afirmar que os CLs de Xai-Xai foram criados com base na ideia de gestão democrática, que se fundamenta em diferentes mecanismos de eleição e representação das organizações da sociedade civil. $\mathrm{Na}$ sua constituição, eles combinam em sua configuração, por um lado, a participação direta da população nos bairros para elegerem seus 
representantes e, por outro, a escolha de representantes nos postos administrativos municipais que integram a seguir o $\mathrm{CL}$ da cidade. Eles foram adotados na cidade a partir do ano de 2009.

Conforme já foi assinalado, o objetivo é coproduzir a ação pública local por meio da inserção de representantes das comunidades nas decisões municipais. Vale destacar, no entanto, que a implementação pelo governo central nos dez municípios capitais provinciais do Programa Estratégico para a Redução da Pobreza Urbana (PERPU) voltado para o financiamento das iniciativas empreendedoras de cidadãos munícipes ou de grupos associados está por trás do estabelecimento dos CLs na cidade. Conforme já foi assinalado, o objetivo é coproduzir a ação pública local pela inserção de representantes das comunidades nas decisões sobre

O PERPU faz parte da estratégia que associa a transferência de orçamento previamente definido no nível central e alocado aos entes municipais para o financiamento de projetos apresentados pelos cidadãos e considerados importantes para alavancar 0 desenvolvimento local e reduzir a pobreza da população ao nível das grandes cidades moçambicanas. Os repasses de verbas efetuados pelo governo central para os municípios no âmbito desse programa são condicionados, portanto, à existência de CLs nos municípios contemplados. Nesses termos, importa examinar como ocorrem as ações que se pretendem participativas no contexto dos OPL em Xai-Xai e quais configurações apresentam as práticas de participação cidadã que são implementadas, lembrando que esse município não deve ser tomado para a generalidade da realidade.

\subsubsection{A Dinâmica do Envolvimento dos Cidadãos no Município de Xai-Xai}

No Quadro 2, mostramos que o processo de envolvimento dos cidadãos na gestão municipal é realizado por meio de consultas comunitárias baseadas nos CLs que remetem-nos às iniciativas de participação popular e à promoção do protagonismo da sociedade civil no âmbito do Diploma Ministerial no 67/2009, ao passo que as práticas de governação aberta e de articulação entre gestores municipais e comunidade são na verdade iniciativas das autoridades administrativas municipais (não formalmente regulamentadas) utilizadas como mecanismos que auxiliam 0 exercício da atividade de gestão e da implementação das ações governamentais. São todas de carácter consultivo, exercendo a responsabilidade de emitir opiniões e apreciar determinados assuntos que são apresentados para o aconselhamento, portanto não são de cunho deliberativo.

O estabelecimento dos CLs está amparado no dispositivo normativo citado acima, e a escolha dos seus representantes segue regras específicas para cada grupo de atores ou segmento representado. Contudo, alguns atores importantes, como as autoridades tradicionais e os dirigentes das várias unidades territoriais administrativas do município, já estão previamente inseridos (por determinação da legislação) na composição dos conselhos que são constituídos.
Nesses termos, o CL da cidade de Xai-Xai é composto por 50 membros ou conselheiros. Desse número, 41 são personalidades provenientes dos fóruns comunitários que são constituídos nos quatro postos administrativos existentes no município. Eles são escolhidos dentre os representantes dos comitês e grupos sociais locais que integram esses fóruns ao nível dos diferentes bairros da cidade que compõem cada uma dessas quatro unidades territoriais administrativas do município.

Participam também como membros do conselho o autarca (o prefeito), que é ao mesmo tempo o presidente do órgão e os 4 representantes do poder público municipal oriundos dos postos administrativos que integram o $\mathrm{CL}$ na qualidade de dirigentes dessas unidades territoriais. Integram igualmente o conselho 2 autoridades comunitárias, que são escolhidas e legitimadas pela população de acordo com os costumes da organização social e política tradicional da comunidade e formalmente reconhecidas pelo poder público. As restantes 2 personalidades que completam a composição do conselho são indicadas pelo executivo municipal.

Portanto, de acordo com essa disposição, 34\% são representantes da população que exercem autoridade sobre as respectivas comunidades (os secretários de bairro); 4\% são individualidades que exercem poder no âmbito das instituições políticas tradicionais nas comunidades (autoridades comunitárias, reconhecidas pelo governo municipal); 44\% são representantes de associações de comerciantes, agricultores, pecuaristas e de transportes coletivos (sociedade civil); 6\% são individualidades que exercem liderança religiosa na cidade (autoridades religiosas) e, por fim, $12 \%$ são representantes designados pelo executivo municipal (chefes de postos administrativos, diretores que exercem cargos governamentais e o autarca).

O conselho é constituído por $64 \%$ de homens e $36 \%$ de mulheres, o que mostra uma organização que respeita a cota de $30 \%$ estabelecida pela legislação que regulamenta a criação das arenas de participação pública, como o mínimo a ser observado para a integração do gênero nos CLs.

De acordo com os dados da pesquisa disponibilizados nas atas referentes ao ano de 2009 (período da constituição do conselho e inicio do $1^{\circ}$ mandato), constatamos que a escolha dos representantes do CLs decorreu em reuniões públicas e por indicação das autoridades municipais. Nesse período, participaram na escolha dos membros dos CLs 1.784 cidadãos munícipes, considerando as quatro reuniões constitutivas realizadas ao nível dos quatro postos administrativos existentes. Consta que houve divulgação da realização dos encontros, não sendo possível, no entanto, avaliar o grau, o alcance e os canais de publicização utilizados para o efeito. Vale destacar que o número de participantes na escolha dos membros do conselho é de um universo populacional de 124.216 habitantes da cidade.

Das reuniões realizadas nos postos administrativos municipais participaram 1.126 mulheres e 658 homens. Majoritariamente, $63 \%$ das mulheres participaram a título individual e não em representação de algum grupo de interesse específico. Relativamente aos homens, apenas $7 \%$ estavam associados a algum grupo de interesse. Destacamos, assim, que o reduzido 
grau de associativismo e a baixa consciência e elevado desconhecimento da importância do exercício da cidadania nos diferentes bairros onde esses atores são escolhidos funcionam como restrições sociopolíticas relevantes à participação, podendo inclusive contribuir para enfraquecer a representação política no âmbito dos dispositivos ou práticas adotadas.

As atas não mostram a participação de organizações institucionalizadas ou não institucionalizadas e de grupos populares significativos que se fizeram presentes na escolha dos membros dos conselhos, mas sim os cidadãos como indivíduos. Compreendemos que a implementação de práticas de participação representa algo de certo modo difundido, porém ainda assim pouco entendido pela população, o que pode explicar em parte o grande número de cidadãos ausentes na criação dos CLs devido à ainda fraca compreensão da necessidade de participação conjunta com o executivo municipal.

Doutro modo, os dados da pesquisa mostram que composição do CL da cidade exclui várias organizações civis formais (entidades patronais, sindicatos, movimentos sociais, instituições acadêmicas e organizações não-governamentais), que possuem alguma força (visto que estão mais bem organizados e têm alguma informação e domínio sobre o processo das políticas públicas em áreas específicas) para influenciar os assuntos que são discutidos por esses conselhos de participação na cidade.

Esses atores sociais estão excluídos e impossibilitados de participar das interações políticas e contribuir para construção de um espaço público formado por atores diversificados e, portanto, mais democrático e favorável à ocorrência do diálogo norteado pelos princípios do processo deliberativo. Observamos que esses atores institucionais não foram convidados a participar da escolha dos membros do CL da cidade, apesar da divulgação efetuada. Vale assinalar que existe no conselho uma representação expressiva de secretários de bairro e alguns grupos sociais que estão mais em sintonia com o governo municipal e que, em conjunto, perfazem $78 \%$ dos membros da arena de participação constituída.

Especificamente, os secretários de bairro, após serem eleitos pela população, passam a desempenhar funções políticas e tarefas administrativas inerentes a essa posição, atribuídas oficialmente pelo executivo municipal. Essa postura pode afetar a sua independência e capacidade de expressar os interesses dos respectivos grupos sociais (dos bairros) que representam.

Relativamente aos membros dos CLs provenientes dos grupos de interesse formados majoritariamente por segmentos como comerciantes, agricultores, pecuaristas e transportadores de coletivos, verificamos que a sua escolha não está embasada na competência e qualificação.

De acordo com as entrevistas, tais escolhas derivam do fato de esses atores sociais possuírem uma relativa cultura associativa e experiência política favorecidas pela posição que ocupam na articulação com as autoridades governamentais no âmbito da implementação das respectivas políticas públicas setoriais. Contudo, essa forma de representação pode revelar um fraco engajamento desses grupos sociais na condução de propostas e ações que traduzam os interesses das comunidades locais, assim privilegiando apenas a defesa de interesses dos grupos representados.

Verificamos igualmente que esses grupos não estão vinculados às bases das outras partes da sociedade civil de modo a assegurar uma efetiva prestação de contas aos representados. Assim, compreendemos que esses aspectos mencionados anteriormente podem contribuir para enfraquecer a formação do interesse coletivo e comprometer o aproveitamento dessas arenas políticas para uma boa governança e a inserção da sociedade na elaboração e controle das políticas locais.

De acordo com os dados da pesquisa, o perfil geral dos membros do conselho mostra que $38 \%$ possuem o $12^{\circ}$ ano de escolarização completa, sendo que, maior número dos membros, $52 \%$ possuem o ensino primário e o fundamental. Dos membros do conselho, 78\% possuem atividades profissionais remuneradas, ou são aposentados, ou recebem subsídio do governo, como é o caso das autoridades tradicionais. Existe igualmente um número considerável de mulheres, no total de $18 \%$, que são donas de seu próprio negócio.

A baixa qualificação de grande parte dos membros do conselho como ilustra o estudo pode operar como um fator que limita a sua atuação e expressão de opiniões relevantes técnica e qualitativamente. Em contrapartida, a maior parte dos representantes do governo municipal no conselho possui o ensino superior, o que mostra a existência de diferenças significativas no grau de informação e de capacitação técnica e política entre os diversos grupos de atores que interagem dentro do conselho.

No estudo, constatamos que, das 18 reuniões realizadas (que constam dos cronogramas analisados) pelo conselho, 100\% das matérias ou temas da pauta dos trabalhos foram propostos pelo executivo municipal. Das decisões tomadas pelo órgão, $97 \%$ foram baseadas no argumento e conhecimento técnico dos membros do conselho indicados pelo poder público, o que pressupõe desigualdades na discussão dos assuntos e uma fraca tematização das inquietações e autonomia decisória por parte dos membros do conselho que representam a sociedade civil. Observamos que a atuação dos atores não-governamentais no conselho tende a dificultar a possibilidade de se captarem demandas e se pactuarem interesses específicos dos grupos sociais com menos acesso na articulação com o executivo municipal.

Essas fragilidades que caracterizam a constituição dos CLs podem influenciar de forma ampla a capacidade de sua articulação política. Segundo o relatado nas entrevistas com atores da sociedade civil do fórum provincial das ONGs, o modelo de participação adotado não possibilita uma participação abrangente. Como exemplo, eles citam o fato de nenhuma entidade filiada a esse fórum que representa os grupos geralmente excluídos integrar os CLs e de não serem convidados a participar das reuniões de consulta comunitária promovidas na cidade de XaiXai.

Com as outras duas alternativas de participação implementadas, a governação aberta e a articulação entre 
gestores municipais e comunidade foram estabelecidas em 2005 e se distinguem dos CLs. A primeira funciona como uma atividade governamental caracterizada pela auscultação dos munícipes e apresentação pública dos resultados da implementação dos projetos da governação municipal e o grau de cumprimento das promessas feitas no período eleitoral. Ela compreende a realização de reuniões abertas à participação da população nos postos administrativos duas vezes em cada ano. A segunda refere-se à prática de mobilização da população para integrar os canais de resolução dos problemas nos bairros, que se fundamentam na articulação entre os gestores municipais e a comunidade, por meio da realização de doze reuniões públicas por ano.

Conforme salientado nas entrevistas, esses dois mecanismos de envolvimento das comunidades desempenham um papel preponderante no processo de administração do município, na medida em que se configuram como espaços de equilíbrio da vontade dos governantes e dos interesses da população. Segundo os dados dos relatórios de governação municipal, entre 2009 e 2013 participaram nas reuniões públicas promovidas 18.264 munícipes.

Os processos de interação neles promovidos implicam o envolvimento comunitário na identificação de prioridades pelos cidadãos munícipes e sua incorporação pelo executivo municipal no momento da definição dos planos governamentais a serem implementados futuramente. A estratégia de participação da população funciona na verdade como uma ação que se pretende complementar ao planejamento tecnocrático realizado, uma vez que as metodologias adotadas não remetem automaticamente a momentos de deliberação das políticas públicas pelos cidadãos. Portanto, o que vem desses mecanismos pode ou não ser utilizado pelos responsáveis pelo planejamento municipal.

De acordo com as entrevistas, a identificação dos problemas que afetam as comunidades e definição de prioridades de ação até pode vir da base, mas a solução nunca vem da mesma base em termos de gestão. Por exemplo, as decisões sobre construção de dois supermercados em 2010 e 2013 no centro da cidade não teve em consideração a relevância e necessidade de implantação desse tipo de equipamentos nos bairros com maior número de habitantes.

Notamos, dessa forma, que a formulação e implementação das políticas municipais é feita ao nível do topo, sem envolver muitas vezes os grupos ou cidadãos nelas interessados ou diretamente afetados. Na prática, as ações governamentais chegam já prontas para serem introduzidas nas comunidades sem, contudo, terem sido discutidas a partir das fontes, isto é, nem com a população, nem ao nível dos CLs. Por exemplo, as medidas importantes sobre a distribuição de espaços para habitação na região de Macanwine-Oeste, que servia para a prática da agricultura familiar bem como, a implantação de reguladores de trânsito na zona da cidade baixa em 2012 e 2013, respectivamente, não foram submetidas a amplos processos de discussão nesses espaços de interação social.
Constatamos pelas entrevistas que os mecanismos de articulação estabelecidos estão mais ligados à necessidade de ampliação da legitimidade política do governo municipal e das suas ações de resposta às demandas sociais. Isso mostra que a participação na definição de prioridades realiza-se quando os agentes públicos interagem com as comunidades para buscar subsídios técnicos e informações para fundamentar sua agenda de planejamento realizado nos "gabinetes". Portanto, essas práticas de envolvimento dos cidadãos na gestão municipal servem mais para sustentar as propostas técnicas dos orçamentos a serem executados nas atividades que não foram a priori definidas com as comunidades beneficiárias.

Enfim, podemos afirmar que as práticas de gestão participativa implementadas no contexto municipal de Xai-Xai não proporcionam automaticamente a constituição de um processo de políticas públicas que se revela aberto à ação deliberativa através da sociedade, dos cidadãos. Os mecanismos de participação cidadã apresentados no Quadro 2 têm funcionado somente na fase de auscultação pública, visto que as preocupações e informações trazidas ou identificadas durante as auscultações aos munícipes surgem muitas vezes depois de o plano ter sido aprovado (ao longo do exercício das atividades de governação). Como o sistema de planejamento utilizado atualmente não permite incorporar todas essas preocupações, até mesmo nos planos subsequentes, a sua resolução é feita sem uma participação visível da população.

Além disso, constatamos que o discurso sobre a GP baseado na ideia de interação social e na governação aberta tem sido utilizado essencialmente para legitimar as decisões técnicas previamente tomadas pelo poder público. Assim, a constituição desses espaços enfrenta obstáculos para se estabelecer como alternativas efetivas de opinião e sobretudo de ação, por meio das quais os atores da sociedade civil se inserem na agenda do governo municipal, apresentando demandas e interesses da população que sejam transformados em projetos de políticas públicas a serem implementados.

\section{CONSIDERAÇÕES FINAIS}

O propósito deste trabalho foi discorrer sobre o processo de institucionalização da GP em Moçambique. Focalizamos o processo de envolvimento dos cidadãos na esfera municipal, considerando, para o efeito, as experiências implementadas no município de Xai-Xai. Destacamos que o estabelecimento das instâncias de participação social foi impulsionado pela aprovação da CRM de 1990, que legitimou a constituição de espaços que permitem a integração e colaboração entre os diferentes atores individuais ou coletivos, possibilitando a gestão compartilhada entre o governo e a sociedade.

Com a aprovação, nos anos de 2003 e 2005, de diretrizes que regulamentam a participação da sociedade, tem sido possível o estabelecimento desde 2006 de mecanismos de envolvimento dos cidadãos que têm contribuído, de certo modo, para a redução das práticas clientelistas e patrimonialistas que foram prevalecentes no período em que a gestão das políticas públicas respeitava o 
modelo de administração pública centralista. Espera-se que as instâncias de participação pública deem um novo ímpeto ao exercício da cidadania ativa e fortalecimento da democracia participativa.

As ações da GP em Xai-Xai foram iniciadas em 2009. O estudo realçou tratar-se de um processo que se mostra ainda desafiador, na medida em que suscita a construção de uma sociedade civil organizada e capaz de se articular em torno das questões políticas de interesse local e, dessa forma, estabelecerse como ator que influencia, contesta e interfere positivamente no processo decisório. Ela demanda por parte do governo um comprometimento maior em relação ao potencial de ação que esses espaços apresentam para contribuir para a boa governança, devendo ser aprimorados por meio de maior capacitação de seus membros integrantes como forma de reduzir as assimetrias informacionais e assegurar uma integração de qualidade entre os atores que neles interagem.

Especialmente em relação aos CLs, que são a forma mais importante de participação, importa que seja assegurada a abrangência e maior representatividade dos grupos sociais que não têm acesso a essas arenas de participação. Isto é, na sua constituição, os CLs ainda apresentam falhas, que se configuram como limitações que interferem nos esforços de materialização dos ideais da democracia participativa e da democracia deliberativa.

Os CLs são, no geral, consultivos e propositivos. Apenas em alguns casos dispõem de poder e capacidade fiscalizadora em relação a alguns programas previamente definidos pelo executivo municipal, sobretudo os relacionados à construção de fontes de abastecimento de água e à gestão da terra. Eles não possuem caráter deliberativo e fiscalizador sobre a implementação das políticas públicas, atuando apenas como um mecanismo que auxilia a viabilização da liberação de verbas, e não se encontram integrados em todo o ciclo de planejamento de Xai-Xai.

Eles exercem uma relativa pressão sobre algumas ações e projetos dos municípios cuja definição ou formulação contaram com a sua participação e envolvimento, mas isso acontece frequentemente apenas com os projetos relacionados ao PERPU. Doutro modo, as reuniões promovidas ao nível desses fóruns de consulta pública contam em sua maioria com a participação de cidadãos a título individual e, muitas vezes, com um número reduzido de participantes que representam as organizações civis formais, que possuem maior força para influenciar os assuntos discutidos por esses conselhos de participação social. Em conjunto, essas limitações operam como constrangimentos e podem comprometer a efetividade da ambicionada gestão democrática.

Para pesquisas futuras sobre a GP no contexto municipal moçambicano, torna-se interessante analisar as questões relativas à institucionalização da participação cidadã e as suas ligações e impacto nos resultados das políticas públicas. Finalmente, outro aspecto fundamental a ser explorado se relaciona ao aprofundamento da discussão sobre a efetividade dos conselhos locais e as implicações na eficácia da ação governamental no nível local, aliada ao problema da accountability tanta política quanto administrativa e, portanto, devendo-se avaliar em que medida a GP favorece as relações políticas e o conteúdo da ação pública na gestão municipal.

\section{REFERÊNCIAS}

Bardin, L. (2004). Análise de conteúdo. 3. ed. Lisboa: Edições 70.

Bevir, M. (2011). Governança democrática: uma genealogia. Revista de Sociologia e Política, 19 (39), 103-114.

Brardhan, P. (2002). Decentralization of Governance and Development. The Journal of Economic Perspectives, 16(4), 185-205.

Bryson, J. et al. (2012). Designing public participation processes: theory to practice. Public Administration Review, 73(1), 23-34.

Canhanga, N. (2009). Os desafios da descentralização e a dinâmica da planificação participativa na configuração de agendas políticas locais. In: Brito, L. et al. (Eds.). Cidadania e Governação em Moçambique. Maputo: IESE, 90-118.

Chhotray, V. \& Stoker, G. (2009). Governance theory and practice. A CrossDisciplinary Approach. Houndsmills: Palgrave Macmillan.

Ciresp. (2001). Estratégia global de reforma do sector público: 2001-2011. Maputo.

Cornwall, A. \& Coelho, V. (2007). Spaces for change?: the politics of citizen participation in new democratic arenas. Zed Books.

Crook, R. (2003). Decentralisation and poverity reduction in Africa: the politics of local-central relations. Public Administration and Development, 23(1), 77-88.

Farazmand, A. (2012). Sound governance: engaging citizens through collaborative organizations. Public Organization Review, 12(2), 223241.

Forquilha, S. \& Oree, (2012). A. Transformações sem mudanças? Os conselhos locais e o desafio da institucionalização democrática em Moçambique. In: Brito, L. et al. (Eds.). Desafio para Moçambique 2011. Maputo: IESE, 35-53.

Gaventa, J. \& Barrett, G. (2012). Mapping the outcomes of citizen engagement. World Development, v. 40, n. 12, p. 2399-2410.

Godoy, A. (2010). Estudo de caso qualitativo, In: Godoi, C., et al. Pesquisa qualitativa em estudos organizacionais: paradigmas, estratégias e métodos. São Paulo: Saraiva, 115-145.

Grindle, M. (2007). Good enough governance revisited. Development Policy Review, 25(5), 533-574.

Habermas, J. (1995). Os tres modelos normativos de democracia. Lua Nova, 36, 39-53.

Koch, P. (2013). Bringing power back in: collective and distributive forms of power in public participation. Urban Studies, 50(14), 2976-2992.

Lüchmann, L. (2006). Os sentidos e desafios da participação. Ciências Sociais Unisinos, 42(1), 19-26.

Mattos, P. (2010). Análise de entrevistas não estruturadas: da formalização. In: Pesquisa qualitativa em estudos organizacionais: paradigmas, estratégias e métodos. Godoi, C. K, Bandeira-de-Melo, R, \& Barbosa da Silva, A. (Org.). São Paulo: Saraiva, 347-370

Nguenha, E. (2009). Governação municipal democrática em Moçambique: alguns aspectos importantes para o desenho e implementação de modelos do orçamento participativo. In: II Conferência do IESE sobre Dinâmicas da pobreza e padrões de acumulação em Moçambique. Maputo.

Osborne, S. (2006). The new public governance? Public Management Review, 8(3), 77-387.

Pateman, C. (2012). Participatory democracy revisited. Perspective Politics. 10(1), 7-19.

González, J. (2015). La participación ciudadana como instrumento del gobierno abierto. Espacios Públicos, 18(43), 51-73.

Roberts, N. (2004). Public deliberation in an age of direct citizen participation. The American Review of Public Administration, 34(1), 315353.

Salvador, M. \& Ramió, C. (2011). Institutionalizing participatory democracy and the emergence of an epistemic community in Spanish local government. Journal of Urban Affairs, 33(5), 491-510.

Nabatchi, T. \& Amsler, (2014). Direct public engagement in local government. American Review of Public Administration, 44(1), 635-885.

Smith, G. (2009). Democratic innovations: designing institutions for citizen participation. Cambridge University Press.

Speer, J. (2012). Participatory governance reform: A good strategy for increasing government responsiveness and improving public services? World Development, 40(12), 2379-2398.

Yin, R. (2005). Estudo de caso: planejamento e métodos. 3. ed. Porto Alegre: Bookman 